\title{
Formulation, optimization and characterization of gastro retentive olanzepine microsphere using 32 factorial design.
}

\author{
Deshmukh MT*, Mohite SK \\ Department of Pharmaceutics, Rajarambapu College of Pharmacy, Kasegaon 415404, Maharashtra, India
}

\begin{abstract}
Olanzepine microsphere prepared by external Inotropic gelation technique by using sodium alginate and carbopol $974 \mathrm{P}$ as a polymer and calcium chloride as a cross linking agent. In this formulation combination of sodium alginate and carbopol $974 \mathrm{P}$ used as a polymer that helps to retard the releasing the drug and increases bioavaibility of drug. The Olanzepine microsphere has other characterization is in the term ofdrug content, drug entrapment efficiency, P XRD, Differential Scanning Colorimetry, FTIR, SEM, in vitro drug release and in vivo drug release.

The in vitro release pattern of Olanzepine microsphere studied in $900 \mathrm{ml}$ of $0.1 \mathrm{~N}$ Hydrochloric acids, using USP dissolution apparatus I. The optimized batch F7 shows greater than $80 \%$ of drug release that is due to using carbopol polymer that helps to retarded the drug release at targeted site over the other formulation. Optimized formulation shows better antidepressant action as compare to pure Olanzepine drug.
\end{abstract}

Keywords: Ionic Gelation Technique, Microsphere, in vitro drug release, in vivo studies.

Accepted on May 11, 2020

\section{Introduction}

Microsphere are characteristically free flowing powder it is solid spherical smooth surface particle size is less than $200 \mu \mathrm{m}$. Microsphere are multiparticulate drug delivery system which are prepared to obtain prolonged or controlled drug delivery to improve bioavailability, stability and to target the drug to specific site at a predetermined rate. The sustained release system used to obtain maximum therapeutic efficacy, it' s most important to deliver the agent to the target tissue in the optimal amount in the right period of time there by causing less toxicity and minimum side effects. Microsphere using as a carrier for a drug its releases drug at a targeted site and shows action [1-3]. Olanzapine is antipsychotic agent belong to thiobenzodiazepines ring. It is a BCS Class II drugs which suffer from poor water solubility and high lipophilicity resulting in a highly variable oral bioavailability. Olanzapine used in treatment of schizophrenia and acute mania in bipolar disorders approved by FDA [4-6]. Despite such wide range applications, of Olanzepine are limited owing to its poor aqueous solubility and hepatic metabolism become difficult to achieve and maintain concentration of Olanzepine within therapeutic range.. Hence formulation of the mucoadhesive microsphere of Olanzapine by using Sodium alginate and carbopol $974 \mathrm{P}$ polymer used to improve residence of dosage form in GIT, reduced dosing frequency and enhance bioavailability in the treatment of schizophrenia [7].

\section{Materials and Methods}

\section{Chemicals}

Table 1. Formulation code.

\begin{tabular}{|c|c|c|c|c|}
\hline $\begin{array}{l}\text { Formulation } \\
\text { code }\end{array}$ & $\begin{array}{l}\text { Drug } \\
\text { ( mg) }\end{array}$ & $\begin{array}{l}\text { Polymer (Carbopol } \\
\text { and Sodium } \\
\text { alginate) gm. }\end{array}$ & $\begin{array}{l}\text { Crosslinking } \\
\text { agent gm. }\end{array}$ & $\begin{array}{l}\text { Distilled } \\
\text { water }\end{array}$ \\
\hline F1 & 200 & 4 & 1 & 100 \\
\hline $\mathrm{F} 2$ & 200 & 5 & 1 & 100 \\
\hline F3 & 200 & 6 & 1 & 100 \\
\hline $\mathrm{F} 4$ & 200 & 4 & 1.5 & 100 \\
\hline F5 & 200 & 5 & 1.5 & 100 \\
\hline F6 & 200 & 6 & 1.5 & 100 \\
\hline F7 & 200 & 4 & 2 & 100 \\
\hline F8 & 200 & 5 & 2 & 100 \\
\hline F9 & 200 & 6 & 2 & 100 \\
\hline
\end{tabular}

Olanzepine is gift sample from the Neuland Lab. Sodium alginate, from Loba chemical, Calcium chloride from SD Fine Chem.Ltd., Carbapol 974P from Coorong Asia Pvt.Ltd 


\section{Olanzepine microsphere prepared by inotropic gelation Technique}

All ingredients were weighed properly according to the formulas given in Table 1.

Carbapol and alginate solution were prepared by initially dispersing the Carbapol $(2 \%-6 \%)$ and sodium alginate $(3 \%$ $\mathrm{w} / \mathrm{v})$ in water by mild heating $\left(50^{\circ} \mathrm{C}\right)$ and stirredby magnetic stirrer. To this dispersion, Olanzapine (200 mg) was added and sonicated for $30 \mathrm{~min}$. Then dispersion was then added drop wise by using 20-gauge hypodermic needle to solution of calcium chloride $(5 \%-10 \% \mathrm{w} / \mathrm{v})$ stirred at $500 \mathrm{rpm}$.

The gelled droplets were allowed to remain in calcium chloride solution for 30 minutes for complete curing, filtered and washed repeatedly but using deionized water in order to remove excess of $\mathrm{CaCl}_{2}$ that might have deposited on surface of microspheres (Table 1). Formed microspheres were dried at $50^{\circ} \mathrm{C}$ under vacuum $[8]$.

\section{Evaluation Parameter}

\section{Drug content}

$10 \mathrm{mg}$ Olanzepine microsphere was crushed and added to 100 $\mathrm{ml}$ of phosphate buffer $\mathrm{pH}$ 6.8. After 30 minutes the solution was filtered and from $10 \mathrm{ml}$ solution $1 \mathrm{ml}$ solution was withdrawn diluted up to $10 \mathrm{ml}$ with phosphate buffer $\mathrm{pH} 6.8$ $(10 \mu \mathrm{g} / \mathrm{ml})$. This solution concentration for the drug content of formulations were calculated using calibrated standard curve equation $y=0.26418 \mathrm{x}+0.018$. The drug content was determined at $\lambda \max 227 \mathrm{~nm}$ by UV-spectrophotometer against blank.

\section{Drug entrapment efficiency}

$50 \mathrm{mg}$ microspheres were powdered and suspended in $50 \mathrm{ml}$ of $0.1 \mathrm{~N} \mathrm{Hcl}$ followed by $30 \mathrm{~min}$. sonication. The solution was kept undisturbed for 24 hours; and filtered. The filtrate recovered was examined spectrophotometrically at $227 \mathrm{~nm}$.

The Drug Entrapment Efficiency was calculated using the following formula:

$\mathrm{EE}(\%)=\mathrm{ED} / \mathrm{AD} \times 100[9]$.

\section{FTIR study}

$10 \mathrm{mg}$ of the sample and $400 \mathrm{mg}$ of $\mathrm{KBr}$ were taken in a mortar and triturated. A small amount of triturated sample was taken into a pellet maker and was compressed at $10 \mathrm{~kg} / \mathrm{cm} 2$ using a hydraulic press. The pellets was kept onto the sample holder and scanned from $4000 \mathrm{~cm}-1$ to $400 \mathrm{~cm}-1$ in SHIMADZU FTIR Spectrophotometer [10].

\section{Differential scanning colorimetry}

Study was carried out to check compatibility between drug and polymer in microsphere form. Samples of $5 \mathrm{mg}$ was placed in aluminum pans (Al-Crucibles, $40 \mu \mathrm{l}$ ) and sealed. The heating was carried out between The thermograms were recorded over a temperature range of $50^{\circ} \mathrm{C}$ to $250^{\circ} \mathrm{C}$ for calibration of instrument at rate of $10^{\circ} \mathrm{C} / \mathrm{min}$ under nitrogen purge gas at 50 $\mathrm{ml} /$ minute and samples were analyzed.

\section{Scanning electron microscopy}

The SEM analysis was carried out using a scanning electron microscope (SPPU-JEOL.). Prior to examination, samples were mounted on an aluminum stub using a double sided adhesive tape and making it electrically conductive by coating with a thin layer of gold in vacuum. The scanning electron microscope was operated at an acceleration voltage of $5 \mathrm{kV}$ and resolution of 4000 . To study surface morphology, the formulation subjected to scanning electron microscopy, the micrograph depicted in Figure 1.

\section{PXRD analysis}

$\mathrm{X}$-ray diffractogram of the drug and drug loaded microspheres were recorded by a diffractogram (Brucker AXS D8) using Cu line as a source of radiation which was operated at the voltage $40 \mathrm{KV}$ and the current $40 \mathrm{~mA}$. All samples were measured in the $2 \theta$ angle range between $5^{\circ} \mathrm{C}-60^{\circ} \mathrm{C}$ [11- 13].

\section{In vitro mucoadhesion studies}

The mucoadhesive properties of the microspheres were evaluated by in vitro wash-off test. A $1-\mathrm{cm}$ by $1-\mathrm{cm}$ piece of rat mucosa was tied onto a glass slide (3-inch by 1 - inch) using thread. Microspheres were spread onto the wet, rinsed, tissue specimen, and the prepared slide was hung onto one of the groves of a USP tablet disintegrating test apparatus. The disintegrating test apparatus was operated such that the tissue specimen was given regular up and down [14].

\section{In vitro drug release}

The release rate of Olanzepine from Olanzepine microspheres was determined using USP Type I dissolution test apparatus. The dissolution test was performed using $900 \mathrm{ml}$ of $0.1 \mathrm{~N}$ Hydrochloric acids, at $37 \pm 0.5^{\circ} \mathrm{C}$ and a rotation speed of 50 rpm. In specified time intervals and aliquot of $5 \mathrm{ml}$ samples of the solution were withdrawn from the dissolution apparatus with replacement of fresh fluid to dissolution medium. The samples were filtered through filter of $0.45 \mu \mathrm{m}$. The samples were analyzed at $227 \mathrm{~nm}$ for drug content using UV spectrophotometer [15].

\section{In vivo study}

The protocol of the present study was approved by IAEC (proposal number RDCOP/ IAEC/ Approval / 2016 - 17/ 02 dated 8.8.2016). In vivo antidepressant activity was carried out using healthy Wistar albino rats and mice of either sex weighing $150 \mathrm{gm}$. to $250 \mathrm{gm}$. were used. To carry out study animals were divided in three groups as control, pure drug treated and microsphere formulation treated. The animals were provided with housing in polypropylene artificial lighting to stimulate day night cycle and access to food and water ad 
libitum. Following test performed to accessing antidepressant efficacy.

Forced swim test: Forced swim tests are conducted by placing rats individually in large glass cylinders $(45 \times 20 \mathrm{~cm})$ containing water approximately $30 \mathrm{~cm}$ deep. The water should be at a height such that the rat cannot escape or touch the bottom of the beaker. On day one, the rat is placed in the cylinder for 15 minutes followed by a second 5 minutes test 24 hours later. Latency to float and amount of time spent struggling are measured.

Tail suspension test: This is a behavioral test useful in the screening of potential of antidepressant drugs. Mice are suspended by their tails with tape, in such a position that it cannot escape or hold on to nearby surfaces. During this test, typically six minutes in duration, the resulting escape oriented behaviors are quantified $[16,17]$.

\section{Stability study}

Study carried out for Olanzapine formulation as per ICH guidelines. The best mucoadhesive microspheres formulation was sealed in high-density polyethylene bottles and stored at $40 \pm 2{ }^{\circ} \mathrm{C} / 75 \pm 5 \%$ relative humidity (RH) for 90 days. The samples were evaluated for entrapment efficiency and percentage mucoadhesion for every 1 month to 3 months. At the intervals of each sample were withdrawn and tested.

\section{Results and Discussion}

\section{$U V$ visible analysis}

The absorbance of the sample solution of Olanzepine shows maximum absorption at wavelength $227 \mathrm{~nm}$ in phosphate buffer ( $\mathrm{pH}$ 6.8) regression coefficient is 0.9863 . Which follows beer' s Lambert law (Figure 1).

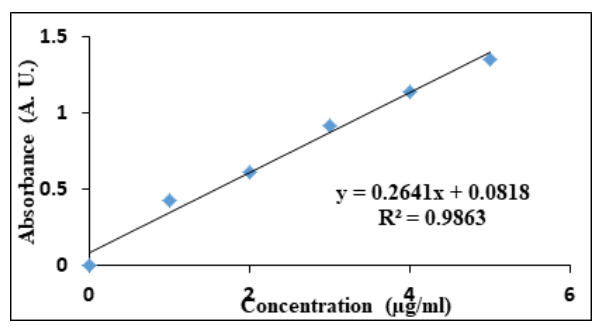

Figure 1. U.V. analysis of Olanzepine API.

\section{FTIR analysis}

It was observed that Olanzapine showed characteristic peak at $3337 \mathrm{~cm}^{-1}$ for - $\mathrm{NH}$ group whereas sodium alginates howed - COgroup at $1670 \mathrm{~cm}^{-1},-\mathrm{OH}$ group at $3100 \mathrm{~cm}^{-1}$ and $-\mathrm{NH}$ group at $3563 \mathrm{~cm}^{-1}$ While Carbopol showed - COgroup at $1653 \mathrm{~cm}^{-1}$ However shift in - CO group peak of polymer( alginate) and - NHgroup of Olanzapine to 1696 $\mathrm{cm}^{-1}$ and $3563 \mathrm{~cm}^{1}$ suggested possibility of $\mathrm{H}$ - bonding between drug and polymer (Figure 2).
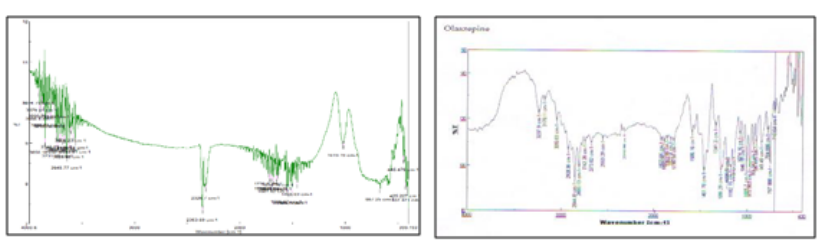

Figure 2. (A) FTIR spectra of Olanzepine microsphere (B) FTIR spectra of Olanzepine API.

\section{Differential scanning colorimetry}

The thermal behavior of prepared Olanzapine microspheres (Figure 3) was studied in comparison with thermograms of pure Olanzapine as shown. The thermogram of pure Olanzapine showed a sharp endothermic peak at $195^{\circ} \mathrm{C}$ whereas formulation containing Olanzapine showed 2 melting endotherm at $126.95^{\circ} \mathrm{C}$ and $190.14^{\circ} \mathrm{C}$ which correspond to melting pt. of polymer and drug indicating that there is no interaction between drug and polymer [17].
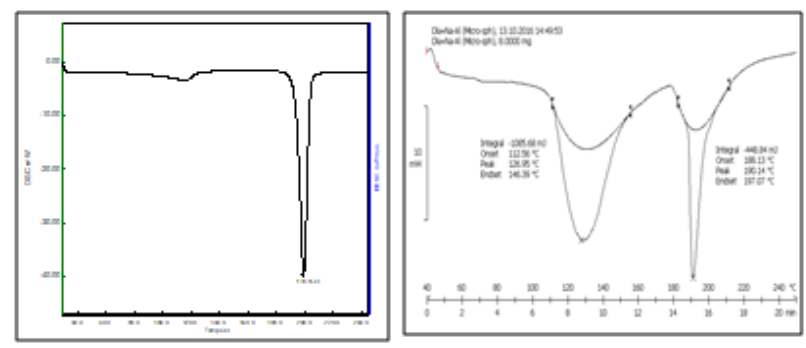

Figure 3. (A) DSC of Olanzepine API. (B) DSC of Olanzepinemicrospher Scanning Electron Microscopy (SEM).

The surface of the Olanzepine microspheres was rough due to a higher concentration of polymers and uniformly dispersed of drug molecular level in matrices (Figure 4).

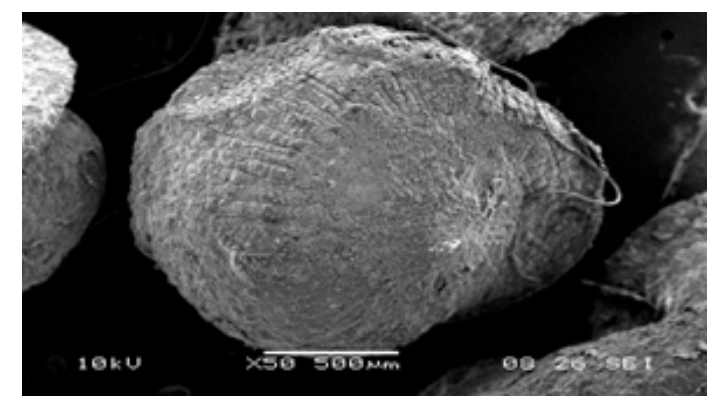

Figure 4. SEM of prepared Microsphere.

\section{PXRD analysis}

The XRD of Olanzepine showed sharp peaks depicting a typical crystalline pattern. However Olanzapine loaded mucoadhesive microspheres showed less intense peaks, revealing that some amount of Olanzapine was changed to amorphous form. Thus it can be concluded that the polymorph of the pure drug was the same as that of drug polymorph incorporated in microsphere (Figure 5). 

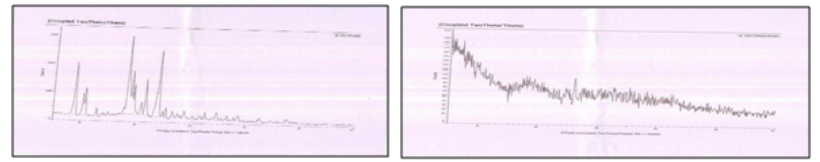

Figure 5. (A) XRD of Olanzepine API (B) XRD of Olanzepine microsphere.

\section{Drug entrapment efficiency}

From data it was observed that increase in the molecular weight of the mucoadhesive polymers increases the drug entrapment efficacy due to increase in the viscosity of the polymeric solution (Figure 6). Greater availability of binding sites in the network of polymeric chains a higher amount of drug entrapped (Table 2).

Table 2. Drug entrapment efficiency.

\begin{tabular}{ll}
\hline Formulation code & Drug content \\
\hline F1 & $3.65 \pm 0.0216$ \\
\hline F2 & $3.12 \pm 0.0216$ \\
\hline F3 & $2.86 \pm 0.0216$ \\
\hline F4 & $3.9 \pm 0.2160$ \\
\hline F5 & $3.32 \pm 0.0141$ \\
\hline F6 & $3.03 \pm 0.0294$ \\
\hline F7 & $4.1 \pm 0.2449$ \\
\hline F8 & $3.56 \pm 0.0432$ \\
\hline F9 & $3.2 \pm 0.1414$ \\
\hline
\end{tabular}

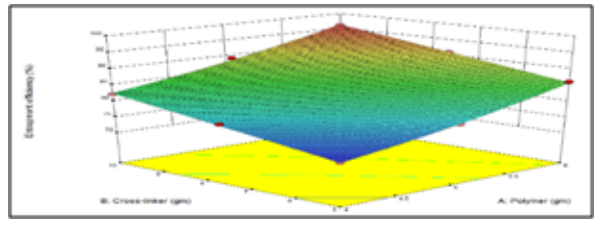

Figure 6. Drug entrapment efficiency.

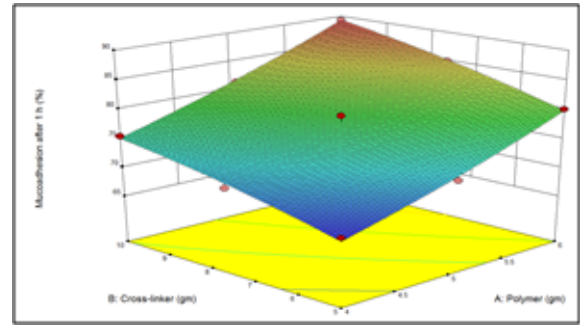

Figure 7. In vitro wash off test.

The study of in vitro wash off test revealed that all the batches of prepared microspheres had good mucoadhesive property ranging from $68.12 \%$ to $81.3 \%$ (Figure 7 ). On increasing the polymer concentration, the mucoadhesive property of the microspheres also increased (Table 3).

Table 3. \% In vitro wash off test.

\begin{tabular}{ll}
\hline Formulation code & $\begin{array}{l}\% \text { of microsphere adhered to } \\
\text { mucous membrane }\end{array}$ \\
\hline F1 & $68.12 \pm 0.014$ \\
\hline F2 & $72.39 \pm 0.029$ \\
\hline F3 & $80.12 \pm 0.008$ \\
\hline F4 & $71.1 \pm 0.081$ \\
\hline F5 & $79 \pm 0.141$ \\
\hline F6 & $85 \pm 0.355$ \\
\hline F7 & $75.5 \pm 0.374$ \\
\hline F8 & $81.3 \pm 0.294$ \\
\hline F9 & $80.31 \pm 0.008$ \\
\hline
\end{tabular}

Table 4. \% Drug release.

\begin{tabular}{ll}
\hline Formulation code & In vitro Dissolution (\%) \\
\hline F1 & $96.47 \pm 1.0509$ \\
\hline F2 & $90.2 \pm 1.0816$ \\
\hline F3 & $87.35 \pm 1.02943$ \\
\hline F4 & $88.37 \pm 1.0509$ \\
\hline F5 & $82.58 \pm 1.04320$ \\
\hline F6 & $78.19 \pm 1.04546$ \\
\hline F7 & $80.17 \pm 1.02160$ \\
\hline F8 & $78.64 \pm 1.00816$ \\
\hline F9 & $75.89 \pm 1.43320$ \\
\hline
\end{tabular}

\section{In vitro drug release studies}

The $\%$ drug release is observed to increase with decreased concentration of Carbapol. The regression coefficient (r2) value of the was found to be 0.9971 showed excellent correlation between polymer conc. and drug release. \% drug release was observed to increase with decreased concentration of Carbapol due to formation of a polymeric coat around the Olanzapine drug which retards the drug release as the concentration of Carbapol and sodium alginate polymer (Figure 8).The decrease in conc. of polymer, gives less compact beads and provides lesser no. of binding sites along alginate chains for $\mathrm{Ca}^{+2}$ (Tables 4 and 5). 


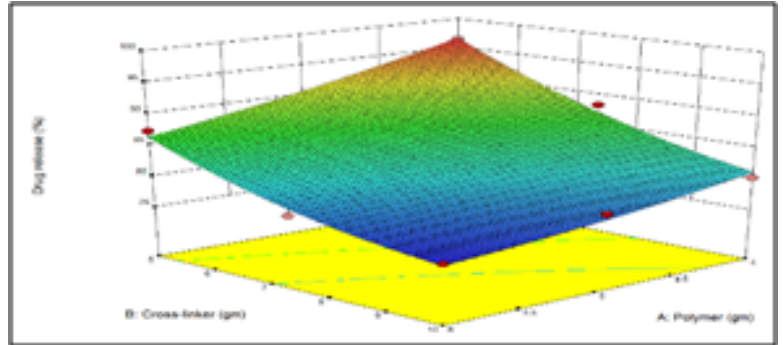

Figure 8. In vitro drug release.

Table 5. Regression coefficient (R2) value of different kinetic model.

\begin{tabular}{llll}
\hline Formulation code & $\begin{array}{l}\text { Zero } \\
\text { Model }\end{array}$ & $\begin{array}{c}\text { Order } \\
\text { First-Order } \\
\text { Model }\end{array}$ & Higuchi Model \\
\hline F1 & R2 & R2 \\
\hline F2 & 0.9012 & 0.8932 & 0.9439 \\
\hline F3 & 0.9397 & 0.9611 & 0.9771 \\
\hline F4 & 0.9752 & 0.9673 & 0.9841 \\
\hline F5 & 0.9195 & 0.9521 & 0.9512 \\
\hline F6 & 0.9443 & 0.9613 & 0.9623 \\
\hline F7 & 0.9517 & 0.9532 & 0.9701 \\
\hline F8 & 0.9639 & 0.9194 & 0.9754 \\
\hline F9 & 0.9532 & 0.9641 & 0.9663 \\
\hline
\end{tabular}

\section{In vivo study}

In vivo efficiency of the prepared batch was performed in healthy normal Wistar rats by measuring the antidepressant effect produced after oral administration. The $72 \mathrm{mg}$ Olanzepine microsphere equivalent to $5 \mathrm{mg}$ of drug was administered and used for the study.

Table 6. Forced swimmimg and immobility time.

$$
\text { Swimming time (s) Immobility Time (s) }
$$

s.

\begin{tabular}{|c|c|c|c|c|c|c|c|}
\hline & Treatment & $15 \mathrm{~min}$ & $\begin{array}{l}30 \\
\min \end{array}$ & $\begin{array}{l}60 \\
\min \end{array}$ & $\begin{array}{l}15 \\
\min \end{array}$ & $\begin{array}{l}30 \\
\min \end{array}$ & $\begin{array}{l}60 \\
\min \end{array}$ \\
\hline 1 & Normal (Saline) & $\begin{array}{l}139.34 \\
\pm 1.57\end{array}$ & $\begin{array}{l}152.67 \\
\pm 1.66\end{array}$ & $\begin{array}{l}146.67 \\
\pm 2.37\end{array}$ & $\begin{array}{l}59.34 \\
\pm \\
1.25\end{array}$ & $\begin{array}{l}64.50 \\
\pm \\
2.62\end{array}$ & $\begin{array}{l}65.67 \\
\pm \\
1.19\end{array}$ \\
\hline 2 & $\begin{array}{l}\text { Std (Olanzepine; } 10 \\
\mathrm{mg} / \mathrm{kg} \text {, imp.) }\end{array}$ & $\begin{array}{l}175.834 \\
\pm 1.75\end{array}$ & $\begin{array}{l}168.17 \\
\pm 1.68\end{array}$ & $\begin{array}{l}166.34 \\
\pm 1.66\end{array}$ & $\begin{array}{l}49.00 \\
\pm \\
2.06\end{array}$ & $\begin{array}{l}40.00 \\
\pm \\
2.06\end{array}$ & $\begin{array}{l}35.34 \\
\pm \\
2.33\end{array}$ \\
\hline 3 & $\begin{array}{l}\text { Test } \\
\text { (So.alginate\&Carbopol } \\
\text { ) }\end{array}$ & $\begin{array}{l}176.50 \\
\pm 2.31\end{array}$ & $\begin{array}{l}213.50 \\
\pm 2.67\end{array}$ & $\begin{array}{l}227.67 \\
\pm 2.26\end{array}$ & $\begin{array}{l}57.17 \\
\pm \\
2.61\end{array}$ & $\begin{array}{l}34.84 \\
\pm \\
1.91\end{array}$ & $\begin{array}{l}32.84 \\
\pm \\
2.39\end{array}$ \\
\hline
\end{tabular}

Effect of acute treatments of Olanzepine API and Olanzepine - Carbapol and sodium alginate microsperes in FST:Animals from group I (normal), submitted to a $5 \mathrm{~min}$
FST in second session after $24 \mathrm{~h}$ of first habituation session on day 1 , showed increased duration of immobility and decreased swimming duration. (Table 5 and Figure 9), indicating induction of depression like state in animals. Animals from group II (Olanzepine); group III (Carbapol and sodium alginate ) showed significant decrease in duration of immobility and increase in swimming duration on day 1 as compared to group I (normal). However, effectiveness of Carbapol microsperes was more than the API olanzapine (Table 6 and Figure 10). In FST., the duration of swimming of animals in treatment groups are increased as compared to the animals in normal group animal. The immobility time was significantly reduced in all treatment animals and an improved activity was seen in the animals treated with microsphere formulation.

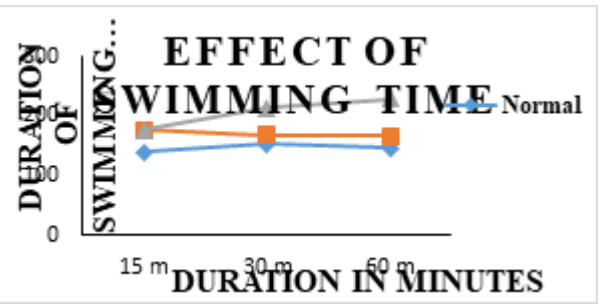

Figure 9. Effect of swimming time.

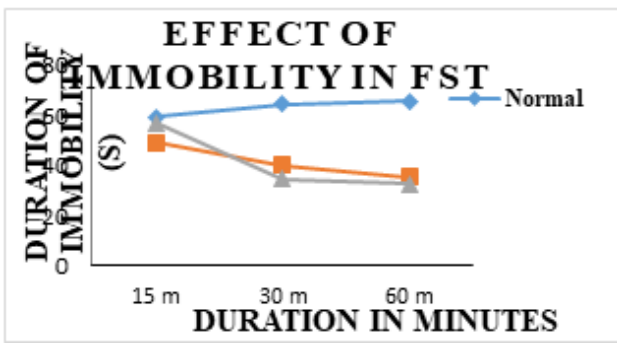

Figure 10. Effect of immobility in FST.

Table 7. Immobility in TST.

Observations

\begin{tabular}{lll}
\cline { 2 - 3 } Treatment & Immobility Time (Before) & $\begin{array}{l}\text { Immobility } \\
\text { (After) }\end{array}$ \\
\hline Normal(Saline) & $115.84 \pm 2.157$ & $120.50 \pm 2.985$ \\
\hline Std (Olanzepine API) & $118.00 \pm 1.907$ & $56.84 \pm 2.552$ \\
\hline Test(Sod.alginate\&carbopol) & $141.67 \pm 2.270$ & $48.34 \pm 1.216$ \\
\hline
\end{tabular}

Duration of immobility of animals from group I (normal), submitted to a 6 min TST on day 1, was increased (Figure 10), indicating induction of depression like state in animals. 


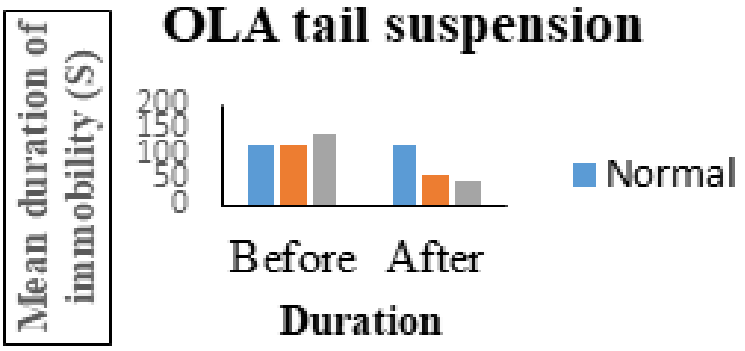

Figure 10. Effect of tail suspension test.

\section{Conclusion}

Olanzepine microsphere prepared by inotropic gelation method using carbopol and sodium alginate polymer. Carbopol and sodium alginate combination played an important role in drug release rate. Drug release rate decreased as increasing concentration of polymer. Drug Release rate it has been observed that the drug release rate decreases with time due to increasing concentration of polymer. Reason behind this isdue to formation of a polymeric coat around the Olanzapine drug which retards the drug release as the concentration of Carbapol and sodium alginate polymer. The decrease in conc. of polymer, gives less compact beads and provides lesser no. of binding sites along alginate chains for $\mathrm{Ca}^{+2}$. Drug Release up to 6 hour. when compared to those formulations containing concentration of pectin. The finalize batch characterize by the Drug Release test was found to be greater than $80.00 \%$.

Pre-formulation studies of microsphere such as determination of $\chi \max (\mathrm{UV})$, Identification study (FTIR), thermal studies (DSC), XRD were carried out to check purity, quality of drugs used and confirm cross linking between drug and polymer. The drug-excipients compatibility study were carried out by using FTIR in order to check compatibility and found that components of the formulation were compatible with each other as there was no significant changes in IR spectra for various physical mixtures. The baseline in the DSC thermogram was observed with absence of any exothermic peak. The absence of exothermic peaks clearly indicates the stability of the mixture.

The prepared microsphere of Olanzapine was found to show good drug entrapment, percent mucoadhesion, in vitro release and in vivo release. The responses observed for all the formulations prepared were fitted to various models using Design- Expert ${ }^{\circledR}$ software. Advanced study such as morphology by SEM was found to show good results. Analysis of experimental results was done by using the Design Expert to optimize formulation of microsphere.

In vivo efficiency of the best found formulation of Olanzapine prepared by using Carbopol polymer was performed on healthy normal wistar albino rats by measuring the antidepressant effect produced after oral administration. When Olanzapine microsphere administered, the duration of swimming of animals in treatment groups are increased as compared to the animals in normal group and immobility time was significantly reduced in all treatment animals and an improved activity was seen in the animals treated with combination of carbopol and sod. alginate formulation.

In mucoadhesive microspheres of Olanzepine was successfully prepared by ionic gelation method. The microspheres prepared exhibited good mucoadhesive and drug release capacity. Developed microspheres were suitable for controlled release effect after oral administration of drug. Thus the microspheres of Olanzepine showssustain the release and increase in patient compliance.

\section{Conflict of Interest}

None

\section{References}

1. Parmar H, Bakliwal S, Gujarathi N, et al. Different methods of formulation and evaluation of mucoadhesive microsphere. Int J Appl Biol Pharmaceut Tech.2010; 3:1157-1167.

2. Alagusundaram M, Chetty $M$, Umashankari $\mathrm{K}$, et al. Microspheres as a novel drug delivery system: A review. Int J Chem Tech Research. 2009; 1: 526- 534.

3. Hejazi R, Amiji M. Chitosan based gastrointestinal delivery systems. J Cont Rel. 2003; 89:151-65.

4. VenkateskumarK, Arunkumar N, Verma P, et al. Characterization of Olanzapine-solid dispersions.Int J Pharma Res Devel. 2010; 10:13-24.

5. Patel C, Sahoo U, Seth A, et al. Formulation and evaluation of solid dispersion of Olanzepine. Int J Pharma Pharmaceut Sci. 2011; 1598-1605.

6. Amir B, Fazal S, Khalid R. Controlled Release Matrix Tablets of Olanzapine: Influence of Polymers on the In Vitro Release and Bioavailability. AAPS Pharm Sci Tech. 2010; 11:1397-1404.

7. Sahu S, Chourasia A, Toppo A, et al. Formulation and evaluation of captopril microspheres by ionic gelation technique.Int J Pharma Life Sci. 2012; 3: 1377-1379.

8. Ararath D, Velmurugan S. Formulation and evaluation of Nevirapinemucoadhesive microspheres; madhurideshmukh9@yahoo.comInt J Pharmaceut Sci. 2015; 7:342-348.

9. Sharma S, Aggarawal G, Dhawan S. Design and evaluation of Olanzepine transdermal patches containing vegetable oils as permeation enhancers. Der Pharmacia Lettre. 2010; 2: 84-96.

10. Sahu S, Chourasia A, Toppo A, Asati A. Formulation and evaluation of Captopril microspheres by ionic gelation technique; Int JPharma Life Sci. 2012; 3: 1377-1379.

11. Garg A, Garg B, Kumar R. Formulation and evaluation of solid dispersions of Olanzapine; Ame Jo Pharmaceut Res. 2014; 4 : 1-5.

12. Venkateswaramurthy N, Sambathkumar R, Vijayabaskaran $\mathrm{M}$, et al. Formulation and in vitro evaluation of 
furazolidonemucoadhesive microspheres.Int $\mathrm{J}$ Pharm Pharmaceut Sci. 2010; 2: 104-106.

13. SonawaneS,Bhalekar M, Shimpi S. Preparation and evaluation of microsphere of xyloglucan derivative. Int $\mathrm{J}$ Biol Macromol. 2014; 69:499-505.

14. Patil S, Choudhary B, Rathor A, et al. Enhanced bioavailability oral andanticancer activity of novel curcumin loaded mixed miscelle in human lung cancer cells. Phytomedicine.2015; 22: 1103-1111.

15. Porsolt RD, Bertin A, Jalfre M. Behavioural despair in rats: a new model sensitive to antidepressant treatments. Eur J Pharmacol. 1978; 47:379-391

16. Jain J, Bhore P, Parmar J, Shaikh A. Antidepressant activity of cordiadichotoma leaf extracts in animal behaviour models: a research. Int J Drug FormulRes. 2010; 1; 294-310.

17. Stability Testing of New Drug Substance and Product. ICH Topic Q 1A (R2). 2003.x

*Correspondence to

Madhuri Deshmukh

Department of Pharmaceutics

Rajarambapu College of Pharmacy

Maharashtra, India

E-mail: madhurideshmukh9@yahoo.com 